\title{
The Status of Domestic Water Demand: Supply Deficit in the Kathmandu Valley, Nepal
}

\author{
Parmeshwar Udmale ${ }^{1, *}$, Hiroshi Ishidaira ${ }^{1}$, Bhesh Raj Thapa ${ }^{1}$ and Narendra Man Shakya ${ }^{2}$ \\ 1 Interdisciplinary Research Center for River Basin Environment (ICRE), University of Yamanashi, \\ Takeda 4-3-11, Kofu, Yamanashi 400-8511, Japan; ishi@yamanashi.ac.jp (H.I.); bthapa.ioe@gmail.com (B.R.T.) \\ 2 Department of Civil Engineering, Institute of Engineering, Tribhuvan University, Lalitpur, Nepal; \\ nms.ioe@gmail.com \\ * Correspondence: pd.udmale@gmail.com; Tel.: +81-552-20-8669
}

Academic Editor: Marco Franchini

Received: 11 March 2016; Accepted: 6 May 2016; Published: 11 May 2016

\begin{abstract}
United Nations Sustainable Development Goal 6 targets access to water and sanitation for all people in the next 15 years. However, for developing countries such as Nepal, it is more challenging to achieve this goal given its poor infrastructure and high population growth. To assess the water crisis in the most developed and populated area of Nepal, the Kathmandu Valley, we estimated available water resources and domestic water demand in the valley. We estimated a supply deficit of 102 million liters per day (MLD) in 2016, after completion of the first phase of the Melamchi Water Supply Project (MWSP). If the MWSP is completed within the specified timeframe, and sufficient treatment and distribution infrastructure is developed, then there would be no water deficit by 2023-2025. This indicates that the MWSP will make a significant contribution to the valley's water security. However, emphasis must be given to utilizing all of the water available from the MWSP by developing sufficient water treatment and distribution infrastructure. Alternate mitigation options, such as planning land use for potential recharge, introducing micro- to macro-level rainwater harvesting structures, conjunctive use of surface and groundwater resources, and water demand-side management, would also be helpful.
\end{abstract}

Keywords: urbanization; water consumption; water supply; water resources

\section{Introduction}

United Nations Sustainable Development Goals (SDGs) [1], which aim to end poverty, protect the planet, and ensure prosperity for all, are scheduled to be achieved over the next 15 years. Of the 17 SDGs, Goal 6 aims to ensure access to water and sanitation for all people. Presently, approximately 663 million people in the world are without access to improved drinking water sources and about 1.8 billion are using drinking water that is fecally contaminated [1]. SDG 6 targets universal and equitable access to safe and affordable drinking water and adequate sanitation facilities for all people by 2030. It will be more challenging to achieve these targets in resource-poor developing countries. Nepal, a developing country in South Asia, had a total population of about 26.49 million in 2011, which was expected to reach 28.47 million by 2016 [2]. According to a report by the Department of Water Supply and Sewerage, Nepal's water supply coverage was $83.59 \%$, and the sanitation coverage $70.28 \%$, in 2014 [3]. To achieve SDG 6, Nepal should invest more in water supply and sewage system infrastructure; when doing so, it needs to consider the increasing population and lifestyle changes, as well as the available water resources.

The Kathmandu Valley (Figure 1) is the most urbanized and populated area of Nepal; it has three districts, Kathmandu, Lalitpur, and Bhaktapur, and is developing in an unplanned manner without proper land use planning. The valley is characterized by acute water shortage and degraded water 
quality due to rapid increases in the population and the degree of urbanization. The deteriorating water quality has a subsequent impact on public health. Kathmandu Upatyaka Khanepani Limited (KUKL) is responsible for the operation and management of the water supply and wastewater services in the valley. The government of Nepal's capital investment and asset management program of 2010 aims to provide 135 liters per capita per day (lpcd) of domestic water to the residents of the valley by 2025 [4]. Rapid and largely unplanned urban and population growth, a lack of sustainable water sources, dramatic land use changes, socioeconomic transformation, and a poor management system have resulted in low availability of potable water in the valley. According to a report by the Asian Development Bank [4], inadequate access to water has led to increased disease incidence, health risks and associated economic burdens, which disproportionately impact the poor and vulnerable population of the valley. Also, seasonal variability in the availability and cost of pure water, and inter-sectoral water conflicts, threaten water security in the valley.

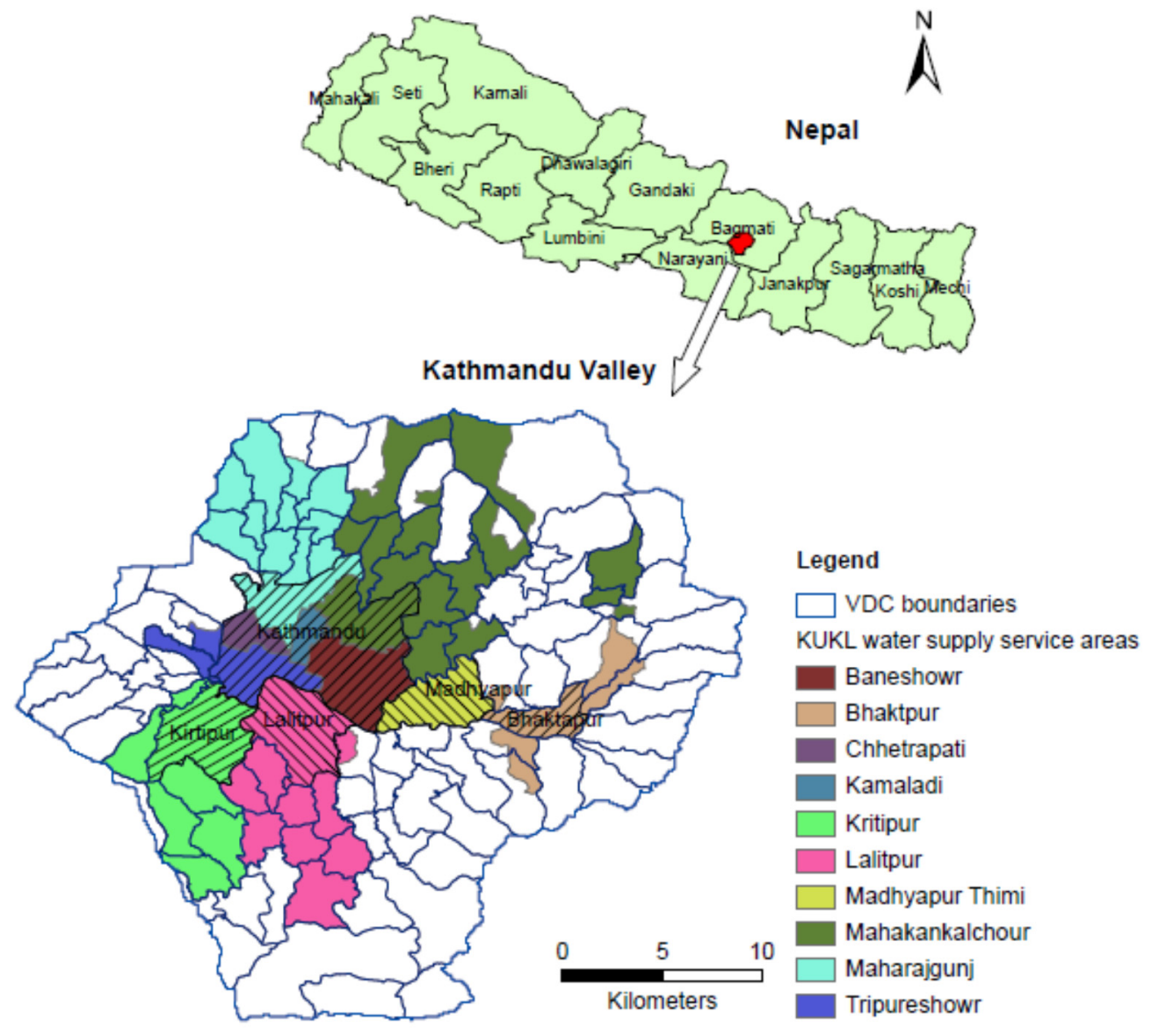

Figure 1. Location of the Kathmandu Valley. Five metropolitan areas are shown with hatches.

These water security problems have motivated efficient and cost-effective water management strategies, through the accurate estimation of domestic water demand and available fresh water resources, as well as priority-setting, to cope with these problems. Water demand varies with the socioeconomic status of households, the setting (rural or urban), and existing infrastructure, etc., but in most cases, relevant data is not available to local administrative divisions in developing countries (including wards and villages in the Kathmandu Valley). In this context, we investigated the available water resources and domestic water demand in the Kathmandu Valley in a preliminary analysis. We present concise insights into the current and future status of domestic water demand in the valley, and the effect of the Melamchi Water Supply Project (MWSP) on the existing supply deficit, thereby 
highlighting the seriousness of the valley's water crisis. Potential methods to mitigate the water crisis in the immediate future are also discussed.

\section{How Large is the Domestic Water Demand?}

The population of the Kathmandu Valley grew from 1.59 million in 2001 to 2.42 million in 2011 [5,6]; it is expected to reach 3.08 million in 2016. When we assume a uniform demand of $135 \mathrm{lpcd}$, then the total demand in the valley becomes 415.5 million liters per day (MLD), which is expected to increase to 540.3 MLD by 2021 (Table 1). Using the Bureau of Indian Standards (BIS) guidelines [7], water demand in the valley is estimated to be 366 MLD in 2016 (present) and is expected to reach about 482 MLD by 2021 (over the entire valley area, i.e., including all KUKL service areas) (See Supplementary Materials). Table 1 gives the population and corresponding estimated water demand in the valley for the period 2001-2021. These figures do not include $20 \%$ leakage (physical losses) through distribution networks [8]. Figure 2 shows Village Development Committee (VDC) and municipality-wide demand in the valley using BIS guidelines. Presently (2016), Kathmandu Metropolitan City, Lalitpur Sub-metropolitan City, and the Madhyapur Thimi, Bhaktapur, and Kirtipur Municipalities have the highest water demand due to their highly dense populations and various lifestyle changes (such as the adoption of full flushing toilet facilities connected to the public sewage system, etc.). Table 2 gives the KUKL service area estimated water demand using BIS guidelines.
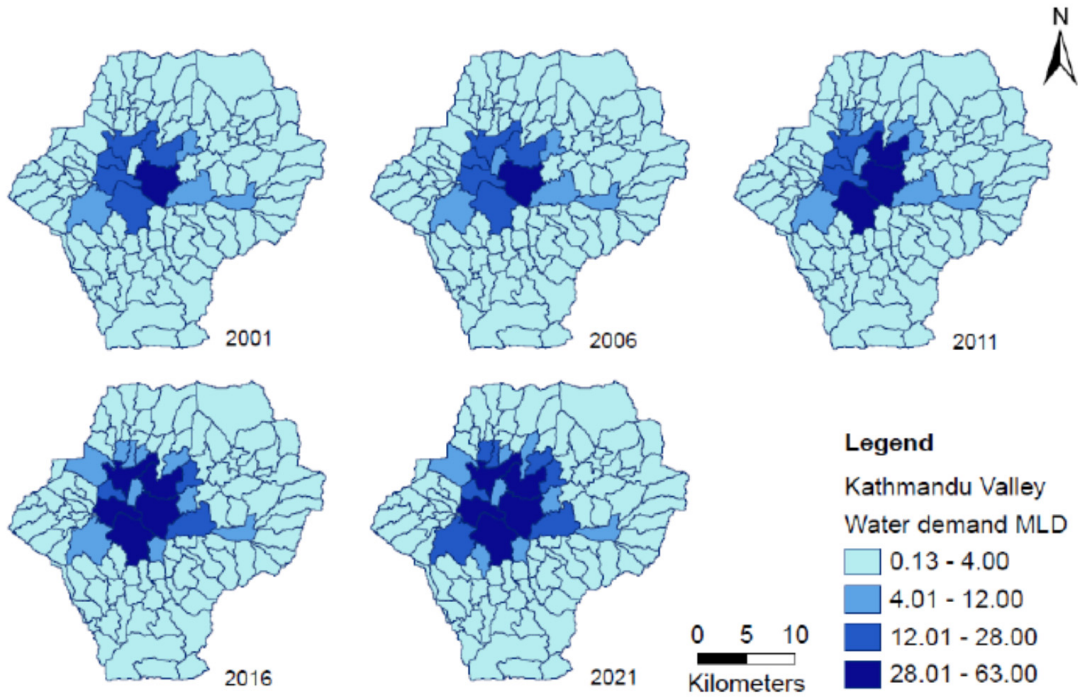

Figure 2. Village Development Committee (VDC)/municipality domestic water demand using Bureau of Indian Standards (BIS) guidelines. Kathmandu Metropolitan City, Lalitpur Sub-metropolitan City, and the Madhyapur Thimi, Bhaktapur, and Kirtipur Municipalities have the highest water demand due to their highly dense populations.

Table 1. Estimated water demand in the Kathmandu Valley. The BIS guidelines are based on water use that varies by setting (rural or urban), water supply and sanitation coverage (instead of assuming constant water demand). Water demand over the KUKL service area is expected to rise to 482 MLD by 2021.

\begin{tabular}{|c|c|c|c|c|c|c|}
\hline \multicolumn{2}{|l|}{ Year } & 2001 & 2006 & 2011 & 2016 & 2021 \\
\hline \multicolumn{2}{|c|}{ Kathmandu Valley population (in millions) } & 1.59 & 1.95 & 2.42 & 3.08 & 4.00 \\
\hline \multirow{2}{*}{ Water demand in the valley (MLD) * } & Assuming 135 lpcd & 214.6 & 262.8 & 327.1 & 415.5 & 540.3 \\
\hline & Using BIS guidelines & 183.9 & 224.9 & 282.5 & 366.0 & 481.5 \\
\hline
\end{tabular}

* MLD, million liters per day; lpcd, liters per capita per day; BIS, Bureau of Indian Standards. Note: Projected population in 2016 and 2021. Leakages during water distribution are not considered within the calculations. 
Table 2. Kathmandu Upatyaka Khanepani (KUKL) Service Area estimated water demand using BIS guidelines.

\begin{tabular}{ccccccc}
\hline \multirow{2}{*}{ KUKL Service Area } & \multirow{2}{*}{ Supply Capacity $\mathbf{2 0 1 3}$ in MLD * } & \multicolumn{5}{c}{ Domestic Water Demand in MLD } \\
\cline { 3 - 7 } & & $\mathbf{2 0 0 1}$ & $\mathbf{2 0 0 6}$ & $\mathbf{2 0 1 1}$ & $\mathbf{2 0 1 6}$ & $\mathbf{2 0 2 1}$ \\
\hline 1. Baneshowr & 1.2 & 29.6 & 35.7 & 43.0 & 51.8 & 62.4 \\
2. Bhaktapur & 4.6 & 11.3 & 12.1 & 13.1 & 15.0 & 16.4 \\
3. Chhetrapati & 0.5 & 13.3 & 16.0 & 19.3 & 23.2 & 28.0 \\
4. Kamaladi & 0.0 & 4.0 & 4.8 & 5.8 & 6.9 & 8.3 \\
5. Kirtipur & 3.9 & 6.7 & 8.2 & 10.1 & 12.5 & 19.6 \\
6. Lalitpur & 23.7 & 27.5 & 32.4 & 40.1 & 49.7 & 63.2 \\
7. Madhyapur Thimi & 13.6 & 5.5 & 7.3 & 9.6 & 16.3 & 21.5 \\
8. Mahakankalchour & 55.5 & 28.9 & 37.8 & 50.8 & 69.5 & 99.9 \\
9. Maharajgunj & 44.5 & 23.6 & 30.8 & 42.1 & 58.4 & 82.5 \\
10. Tripureshowr & 3.9 & 18.5 & 22.4 & 27.2 & 34.4 & 43.5 \\
KUKL SA only & $\mathbf{1 5 1 . 2}$ & $\mathbf{1 6 8 . 7}$ & $\mathbf{2 0 7 . 5}$ & $\mathbf{2 6 1 . 0}$ & $\mathbf{3 3 7 . 8}$ & $\mathbf{4 4 5 . 3}$ \\
Valley (including KUKL SA) & - & $\mathbf{1 8 3 . 9}$ & $\mathbf{2 2 4 . 9}$ & $\mathbf{2 8 2 . 5}$ & $\mathbf{3 6 6 . 0}$ & $\mathbf{4 8 1 . 5}$ \\
\hline
\end{tabular}

${ }^{*}$ MLD, million liters per day; SA, service area. ${ }^{*}$ Note: From 2017, an additional supply of 170 MLD from MWSP should be considered; however, this would be affected the by the present capacity of the water treatment plant (85 MLD), and is therefore not included in above estimations.

\section{What is the Present Status of Water Supply?}

KUKL is an authorized agency supplying potable water to the Kathmandu Valley; it taps water in mountainous (conservation) zones of the valley, from 22 surface water sources, producing about 65.3 MLD and 131 MLD during the dry and wet seasons, respectively [8]. The available surface water from these conservation zones is estimated to be about 133.88 MLD and 199.79 MLD during the dry and wet seasons, respectively [9]. The KUKL is currently harnessing about $49 \%$ and $66 \%$ of the available surface water from mountains during the dry and wet seasons, respectively. This shows that there is scope to harness additional surface water for potable purposes in the valley. According to a previous study by Thapa et al. [9], the estimated groundwater potential in the valley is about 1116 billion liters; however, its use is limited by quality concerns.

The KUKL is responsible for supplying water to its 10 service areas (Figure 1). The maximum domestic water supply capacity of KUKL service areas was reported to be 151.19 MLD in 2013. However, the actual water supplies during the wet and dry seasons are 115 and 69 MLD, respectively. The total water demand in service areas is estimated to be (by considering $135 \mathrm{lpcd}$ ) approximately 361.6 MLD in 2016, with a supply deficit of 210 MLD. The present deficit is currently met through private groundwater pumping, traditional water spouts, wells, supplies from private vendors (through surface, spring, and groundwater), and bottled water industries. This causes over-exploitation of groundwater storage, resulting in drawdown of the groundwater level and drying of wells. The water demand estimated by using BIS guidelines (338 MLD for 2016) gives a supply deficit of about 187 MLD in KUKL service areas (Figure 3). The supply deficit in KUKL service areas in 2021 is estimated to be 322 MLD and 294 MLD, by KUKL and BIS guidelines, respectively, against the present maximum supply capacity of 151.19 MLD and without considering the impact of leakages and the MWSP. 
KUKL Service Area : Water Supply, Demand and Deficit

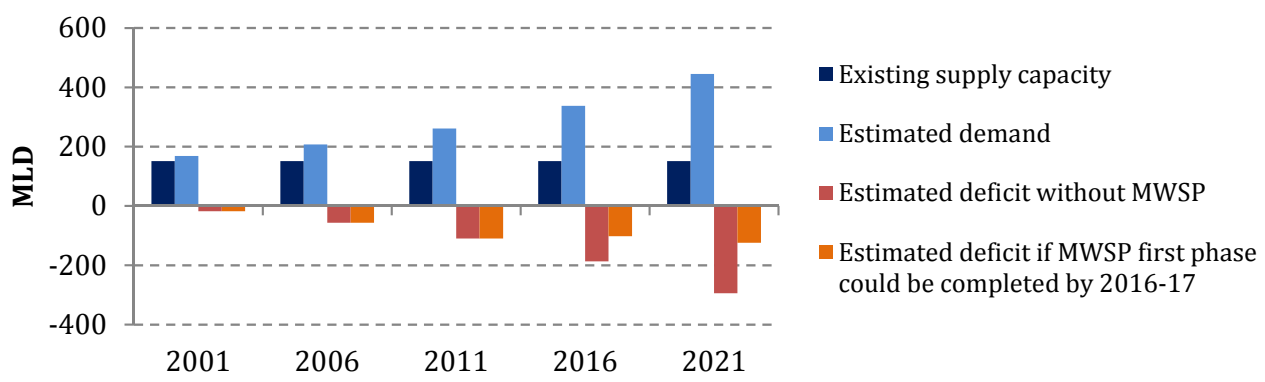

Figure 3. KUKL service area maximum water supply capacity for 2013 and estimated demand deficit. From 2017, an additional supply of 170 MLD from MWSP should be considered; however, this would be affected the by the present capacity of the water treatment plant (85 MLD).

\section{Are Surface and Groundwater Resources in the Valley Drinkable?}

To cope with insufficient surface water resources in the Kathmandu Valley, and to reduce the supply-demand deficit, the use of shallow (small diameter tube wells at the household level and public stone spouts) and deep groundwater resources (by private water vendors, hotels, and industries) is increasing. Nearly half of the valley's total water supply during the wet season, and $60 \%-70 \%$ during the dry season, comes from groundwater sources supplied by KUKL [10]. Recently, KUKL started to drill 40 deep tube wells to supply 40 MLD of water [11]. However, the suitability of groundwater, for drinking purposes, in the area is questionable. The extensive use of groundwater (beyond the rate of recharge), coupled with inadequate management of solid waste and wastewater from urban centers, has increased the vulnerability of the groundwater system to resource depletion, quality degradation, and land subsidence [12,13].

High levels of arsenic, ammonia, and iron in the deep groundwater, and nitrates and E. coli in shallow groundwater, exceeding World Health Organization (WHO) guidelines, have been reported in the Kathmandu Valley [14-17]. A study by Sakamoto et al. [18] showed that almost all water from the rivers and shallow wells in the core valley was not suitable for drinking because of the presence of E. coli, and only $29 \%$ of the deep tube wells had drinkable water [18]. Similar types of studies have identified surface and groundwater contamination (biological and chemical contamination) in the valley, such as those of Jha et al. [19], Dongal et al. [20], Kannel et al. [21], Chapagain and Kazama [15], and Shrestha et al. [22], etc. This poses a limitation on the valley's drinking water resources-in the absence of proper treatment for biological or chemical contamination-in terms of coping with the present water crisis. Shrestha et al. [22] suggested reducing groundwater pollution by improving the sewer line infrastructure and septic tanks through long-term planning. However, treatment of groundwater at the household level, including disinfection, filtration, and boiling before consumption (particularly during the wet season), is recommended to deal with microbial contamination. For the treatment of physicochemical contamination, the simple-in-operation, low cost, and energy efficient ammonia and nitrate removal system developed by Khanitchaidecha et al. [17] could be used at the household or community scale. For iron removal, aeration, sedimentation and filtration before denitrification could be applied, as suggested by Khanitchaidecha et al. [23].

\section{What Will be the Role of the MWSP on Supply Deficit?}

The MWSP is a key initiative of the government of Nepal to supply clean water to the region's 2.5 million people. The first phase (2016-2017) of the project aims to transfer 170 MLD of fresh water from the adjoining Melamchi River (inter-basin transfer) to Kathmandu Valley. The second phase (2016-2023) focuses on source augmentation by transferring 340 MLD from the Yangri and Larke rivers (each with 170 MLD) [4,24]. According to KUKL, the first phase of MWSP will be completed by May 2017 (personal communication; it was originally expected that it would be completed by mid-April 
2016, but was delayed) [25], when it will start pumping 170 MLD of water from the Melamchi River in Sindhupalchok to the valley. However, the Sundarijal water treatment plant, which is under construction and is scheduled to be completed by 2016, has a processing capacity of only 85 MLD, making it impossible to distribute the total 170 MLD of water delivered after Phase One of the MWSP. The remaining excess water $(85 \mathrm{MLD})$ will be released into the Bagmati River until there is a further increase in the treatment and distribution capacity [26]. If we consider the water availability from the MWSP to be 85 MLD, then the total supply capacity will be about 236 MLD in 2016, against the KUKL service area's water demand of 338 MLD. This will result in a deficit of 102 MLD for 2016. The government of Nepal has proposed an additional loan from the Asian Development Bank (ADB) to expand the Sundarijal water treatment plant from 85 MLD to 170 MLD (by 2020), to fully utilize the expected supply delivered by the first phase of the MWSP [4]. If we assume that the full operational capacity of Phase One of the MWSP will be used successfully until 2021, then the remaining supply deficit in service areas will be 124 MLD (Figure 3). This highlights that the valley will be dragged inevitably into another era of chronic water shortages until 2021.

In addition to the existing supply capacity of 151 MLD, completion of Phase Two of the MWSP will provide about 510 MLD of additional water by 2023 . However, its use will depend on the storage and treatment capacities of the valley's water and sanitation infrastructure. If all the water from the MWSP is treated, then it will be sufficient to meet the projected domestic water demand in the Kathmandu Valley (which is approximately 445 MLD for 2021). This will reduce exploitation of groundwater in the valley and highlights the need for planning additional water treatment infrastructure. However, unpredictable factors, such as earthquakes, fuel shortages, and inefficient management competency of contractors, could affect the completion of the project within the specified period, which could in turn lead to exacerbation of the present water crisis in the near future.

\section{How Have Earthquakes Affected the Existing Water Supply?}

A catastrophic earthquake of magnitude 7.6, on 25 April 2015 (and 300 aftershocks greater than magnitude 4.0 until 7 June 2015) took the lives of about 8790 people, as well as causing 22,330 injuries. Approximately eight million people (almost one-third of Nepal's population) have been impacted [27]. The earthquake damage was widespread, covering the entire development infrastructure including water supply pipes, wells and taps (with breaking of underground water supply pipes leading to more pressure on the groundwater). The earthquake caused damage and losses to the water and sanitation sector that were reported to cost NPR 11,379 million (the equivalent of US \$106 million). A recent study by Thapa et al. [9] reported that the valley's water supply infrastructure suffered a reduction in the capacity of water distribution pipe networks of $28 \%, 30 \%$ and $18 \%$ in the Lalitpur, Kathmandu, and Bhaktapur districts, respectively. An approximate $40 \%$ reduction of supplied water by KUKL was also reported, affecting 0.15 and 0.24 million people during the dry and wet seasons, respectively. Repair of those damaged distribution networks may take longer than 1.5 years to complete (personal communication with KUKL, 7 December 2015). Sewerage systems and septic tanks may have also been broken and dislodged by earthquakes, causing leakages that would pollute groundwater. The earthquake has also delayed the construction of the MWSP, which was expected to complete its first phase in April 2016, and has since been postponed to May 2017.

\section{Discussion and Concluding Remarks}

The increase in population is in turn expected to increase pressure on the existing water supply infrastructure of the Kathmandu Valley. The present supply deficit (102 MLD) is expected to increase to 124 MLD after completion of the first phase of the MWSP, assuming KUKL's full supply capacity is realized in 2020-2021. The valley's water crisis should be solved by successful completion of the MWSP (in ideal conditions), with the KUKL's total supply capacity reaching 510 MLD.

The present water crisis will be further exacerbated if the MSWP goals are not achieved in the specified time (i.e., by 2023). Water shortages and poor water quality in the Kathmandu Valley may 
lead to serious health, environmental and socioeconomic consequences. The time and distance to fetch water will cause extra pressure on women's household activities, and may also result in water-related societal conflicts. Poor households are expected to suffer water shortages, resulting in a reduction in water consumption, which subsequently will cause health and sanitation issues. After completion of the MWSP (both phases), about four million people in the valley will have access to sufficient water; however, drinking water quality will remain a challenge. Therefore, this study recommends immediate planning for additional water treatment infrastructure to utilize the water from the MWSP fully by 2023-2025. We conclude that the effect of MWSP on the valley's water supply will be positive in the short term, i.e., by 2023-2025. However, extreme climate change events such as droughts and unforeseen catastrophes such as earthquakes could affect the supply from the MWSP. This could threaten SDG 6, which targets 95\% of the population of Kathmandu Valley having a piped water supply, 99\% having a basic water supply, and 90\% having access to safe drinking water by 2030 [28].

A study by Shrestha [29] suggested alternative options to minimize the demand-supply deficit of the valley-and decrease the stress on groundwater resources-such as the development of urban centers outside the valley, optimum planning of land use for potential recharge, introduction of micro- to macro-level rainwater harvesting structures, and water demand management. The water from the mountainous region, which is also of sufficient quality for drinking purposes, can be harvested with community-based water resources management and used in conjunction with surface and groundwater in the valley. Strategies to save and reuse water, and avoid wastage, should be implemented at the household level.

In addition to water scarcity, the surface and groundwater of the core valley was found to be unsuitable for drinking purposes. Therefore, to use water from the valley (either surface or groundwater) or the MWSP, there is an immediate need for additional water treatment infrastructure. The Sundarijal water treatment plant is expected to utilize water from the first phase of the MWSP by 2020 (170 MLD). However, treatment of the remaining 340 MLD of water is a challenge due to the limited capacity of existing water treatment plants. Additional water treatment capacity needs to be developed by 2023-2025 to treat this remaining 340 MLD of MSWP water. The construction of such infrastructure will require long-term planning and is hugely expensive.

If it is assumed that, under ideal conditions, all the water from the MWSP (510 MLD) is treated and distributed for drinking and other household purposes, then the operation and maintenance of treatment plants will be very expensive, and the risk of water contamination through distribution networks would also be high. Therefore, there is a need to develop small-scale, energy-saving, and highly efficient water treatment systems suited to local conditions. One possible solution could be the development of community- or household-level small water treatment facilities, where people treat water for drinking purposes only and not for other household uses such as bathing, flushing, washing clothes and utensils, and gardening, etc. The present Science and Technology Research Partnership for Sustainable Development (SATREPS) project in Nepal [30] aims to develop water security index maps and an appropriate, locally fitted, compact and decentralized (LCD) water treatment system for groundwater and surface water in the Kathmandu Valley, which is expected to generate practical solutions to deal with water scarcity and quality issues in the valley.

\section{Limitations}

This study used water supply and sanitation statistics for 2011 as constants to estimate water demand according to BIS guidelines. These data may change depending on VDC/municipality-level data availability, or based on the results of a government master plan to obtain $100 \%$ water supply and sanitation coverage by 2017. Furthermore, we did not consider the water supply to areas other than those serviced by the KUKL or the floating (migrant) population in the valley.

Supplementary Materials: The following are available online at www.mdpi.com/2073-4441/8/5/196/s1. 
Acknowledgments: The authors are grateful to the Science and Technology Research Partnership for Sustainable Development (SATREPS)-the Japan Science and Technology Agency (JST), and to the Japan International Cooperation Agency (JICA) project in Nepal, led by Futaba Kazama, for financially supporting this study. The authors also thank the KUKL and MWSP for providing data and information. Finally, the authors express their sincere thanks to Takashi Nakamura, Sadhana Shrestha, and Kamei Tatsuru for their suggestions on dealing with the water scarcity and quality issues in the Kathmandu Valley.

Author Contributions: Hiroshi Ishidaira and Narendra Man Shakya conceived and supervised the study. Parmeshwar Udmale and Bhesh Raj Thapa contributed in the form of data analysis and manuscript preparation.

Conflicts of Interest: The authors declare no conflict of interest.

\section{Abbreviations}

The following abbreviations are used in this manuscript:

BIS Bureau of Indian Standards

KUKL Kathmandu Upatyaka Khanepani Limited

MLD Million Liters per Day

MWSP Melamchi Water Supply Project

VDC Village Development Committee

\section{References}

1. United Nations Organization. Sustainable Development Goals. Available online: http://www.un.org/ sustainabledevelopment/sustainable-development-goals/ (accessed on 9 May 2016).

2. National Population and Housing Census 2011 (Population Projection 2011-2031); National Planning Commission Secretariat, Government of Nepal: Kathmandu, Nepal, 2014.

3. National Management Information Project (NMIP), Nationwide Coverage and Functionality Status of Water Supply and Sanitation in Nepal; Department of Water Supply and Sewerage, Government of Nepal: Kathmandu, Nepal, 2014.

4. $\quad$ Proposed Loan for Additional Financing Nepal: Kathmandu Valley Water Supply Improvement Project; Asian Development Bank: Manila, Philippine, 2015.

5. Nepal Population Census. Available online: https://data.hdx.rwlabs.org/dataset/nepal-population-census2011-cod (accessed on 9 May 2016).

6. Central Data Catalog; National Planning Commission Secretariat, Government of Nepal: Kathmandu, Nepal, 2012. Available online: http://cbs.gov.np/nada/index.php/catalog (accessed on 9 May 2016).

7. IS-1172:1993-Code of basic Requirements for Water Supply, Drainage and Sanitation (Fourth Revision); Water Supply and Sanitation Sectional Committee: New Delhi, India, 1993.

8. Annual Report (Seventh Anniversary); Kathmandu Upatyaka Khanepani Limited: Kathmandu, Nepal, 2015.

9. Thapa, B.R.; Ishidaira, H.; Pandey, V.P.; Shakya, N.M. Impact assessment of Gorkha Earthquake 2015 on potable water supply in Kathmandu Valley: Preliminary analysis. J. Japan Soc. Civil Eng. Ser. 2016, 72, 61-66.

10. International Center for Integrated Mountain Development (ICIMOD). Kathmandu Valley Environmental Outlook; Hillside Press: Kathmandu, Nepal, 2007.

11. For the additional water supply KUKL has started deep boring at 40 different places. Available online: http:/ / www.pahilopost.com/content/-14818.html (accessed on 9 May 2016). (In Nepal)

12. Pandey, V.P.; Chapagain, S.K.; Futaba, K. Evaluation of groundwater of Kathmandu Valley. Environ. Earth Sci. 2010, 60, 1329-1342. [CrossRef]

13. Shrestha, S.; Semkuyu, D.J.; Pandey, V.P. Assessment of groundwater vulnerability and risk to pollution in Kathmandu Valley, Nepal. Sci. Environ. 2016, 556, 23-35. [CrossRef] [PubMed]

14. Khatiwada, N.R.; Takizawa, S.; Tran, T.V.N.; Inoue, M. Groundwater contamination assessment for sustainable water supply in Kathmandu Valley, Nepal. Water Sci. Technol. 2002, 46, 147-154.

15. Chapagain, S.K.; Kazama, F. Overview of chemical quality of groundwater in the Kathmandu Valley. In Kathmandu Valley Groundwater Outlook; Shrestha, S., Pradhananga, D., Pandey, V.P., Eds.; Asian Institute of Technology (AIT): Klong Luang, Pathumthani, Thailand; The Small Earth Nepal (SEN): Kathmandu, Nepal; Center of Research for Environment Energy and Water (CREEW): Kathmandu, Nepal; International Research Center for River Basin Environment-University of Yamanashi (ICRE-UY): Kofu, Yamanashi, Japan, 2012; pp. 49-55. 
16. Pant, B.R. Groundwater quality in the Kathmandu Valley of Nepal. Environ. Monit. Assess. 2011, 178, 477-485. [CrossRef] [PubMed]

17. Khanitchaidecha, W.; Shakya, M.; Tatsuru, K.; Kazama, F. NH4-N removal through nitrification and hydrogenotrophic denitrification in simple attached growth reactors. Water Air Soil Pollut. 2012, 223, 3939-3953. [CrossRef]

18. Sakamoto, S.; Nishida, K.; Kazama, F.; Imaizumi, Y.; Hiraga, Y.; Nakamura, T.; Chapagain, S. Microbial pollution in groundwater and surface water of the Kathmandu Valley. In Kathmandu Valley Groundwater Outlook; Shrestha, S., Pradhananga, D., Pandey, V.P., Eds.; Asian Institute of Technology (AIT): Klong Luang, Pathumthani, Thailand; The Small Earth Nepal (SEN): Kathmandu, Nepal; Center of Research for Environment Energy and Water (CREEW): Kathmandu, Nepal; International Research Center for River Basin Environment-University of Yamanashi (ICRE-UY): Kofu, Yamanashi, Japan, 2012; pp. 56-63.

19. Jha, M.G.; Khadka, M.S.; Shrestha, M.P.; Regmi, S.; Bauld, J.; Jacobson, G. The Assessment of Groundwater Pollution in the Kathmandu Valley, Nepal; Report, Joint Australia (AGSO)-Nepal (GWRDB) Project; Australian Geological Survey Organization: Canberra, Australia, 1997; pp. 1-64.

20. Dongol, B.S.; Merz, J.; Schaffner, M.; Nakarmi, G.; Shah, P.B.; Shrestha, S.K.; Dongal, P.M.; Dhakal, M.P. Shallow groundwater in a middle mountain catchment of Nepal: Quantity and quality issues. Environ. Geol. 2005, 49, 219-229. [CrossRef]

21. Kannel, P.R.; Lee, S.; Lee, Y.S. Assessment of spatial-temporal patterns of surface and ground water qualities and factors influencing management strategy of groundwater system in an urban river corridor of Nepal. J. Environ. Manag. 2008, 86, 595-604. [CrossRef] [PubMed]

22. Shrestha, S.; Nakamura, T.; Malla, R.; Nishida, K. Seasonal variation in the microbial quality of shallow groundwater in the Kathmandu Valley, Nepal. Water Sci. Technol. Water Supply 2014, 14, 390-397. [CrossRef]

23. Khanitchaidecha, W.; Shakya, M.; Nakano, Y.; Tanaka, Y.; Kazama, F. Development of an attached growth reactor for NH4-N removal at a drinking water supply system in Kathmandu Valley, Nepal. Environ. Sci. Health 2012, 47, 734-743. [CrossRef] [PubMed]

24. Freeman, C.; Khanal, N.; Satti, W.; Upreti, A.; Webster, G. Melamchi Water Supply Project. Available online: https:/ / faculty.fuqua.duke.edu/ \{\}charvey/Teaching/663_2014/Pancha/Melamchi_case.pdf (accessed on 9 May 2016).

25. Republica. Melamchi water will reach Kathmandu by May 2017. Available online: http://www.myrepublica. com/economy/story/39554/melamchi-water-will-reach-kathmandu-by-may-2017-adb-veep.html (accessed on 9 May 2016).

26. Thapa, G. Half of Melamchi waters to be used for Bagmati regeneration; The Kathmandu Post: Kathmandu, Nepal, 2015.

27. National Planning Commission (NPC). Nepal Earthquake 2015: Post-Disaster need Assessment Executive Summary; Government of Nepal: Kathmandu, Nepal, 2015.

28. National Planning Commission. Sustainable Development Goals 2016-2030: National (Preliminary) Report; Government of Nepal: Kathmandu, Nepal, 2015.

29. Shrestha, M.N. Groundwater use in the Kathmandu Valley: An analysis of Pre- and Post- Melamchi Scenarios (Chapter 10). In Kathmandu Valley Groundwater Outlook; Shrestha, S., Pradhananga, D., Pandey, V.P., Eds.; Asian Institute of Technology (AIT): Klong Luang, Pathumthani, Thailand; The Small Earth Nepal (SEN): Kathmandu, Nepal; Center of Research for Environment Energy and Water (CREEW): Kathmandu, Nepal; International Research Center for River Basin Environment-University of Yamanashi (ICRE-UY): Kofu, Yamanashi, Japan, 2012; pp. 90-99.

30. Project for Hydro-microbiological Approach for Water Security in Kathmandu Valley, Nepal. Available online: http://www.jica.go.jp/project/english/nepal/008/outline/index.html (accessed on 9 May 2016).

(C) 2016 by the authors; licensee MDPI, Basel, Switzerland. This article is an open access article distributed under the terms and conditions of the Creative Commons Attribution (CC-BY) license (http://creativecommons.org/licenses/by/4.0/). 